\title{
The Study Abroad Experience: A Crucial Element In Globalizing Business School Programs
}

George A. Mangiero, Iona College, USA

Michael Kraten, Suffolk University, USA

\begin{abstract}
Globalization is a fundamental reality of modern business practice. Participation in a study abroad program is a crucial element in helping students become well rounded global business leaders; it is an increasingly important element of a well rounded business curriculum. A semester or summer abroad, properly conceived and designed, can provide enormous benefits to the modern business student. A variety of organizations, including the AACSB, Forum EA, IBEX, and $M S U-C I B E R$, emphasize the benefits of the direct immersion of business students in global environments and settings. This paper presents an innovative model, entitled PACK \& GO, that describes the key elements of a study abroad program for schools, colleges, and universities of business. The model addresses the philosophy, assessment, curriculum, knowledge, governance, and outcomes features of an effective program. The paper concludes with an illustrative example, as well as recommendations for implementation at other institutions.
\end{abstract}

Keywords: Study Abroad; Globalization; Philosophy; Assessment; Curriculum; Knowledge; Governance; Outcomes; Business Schools; Education; Foreign Language; Foreign Cultures; Rome; Australia; Oxford

\section{INTRODUCTION}

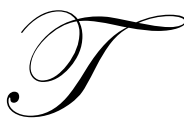

he expanding trend of globalization is transforming American business organizations and necessitating a greater awareness of cultural issues on the part of their employees. Thus, to ensure that their employees are appropriately exposed to global cultures, colleges and universities are remodeling their curricula to emphasize such information. Although written cases and internet based communication methods are now being utilized to expose American students to global practices within American classrooms, many institutions now prefer to require students to physically travel to international locations for significant learning experiences.

A wide variety of academic and governmental organizations, including the AACSB, Forum EA, the United States Department of Education, and MSU-CIBER, have explained how such experiences provide long-term value to students and their future employers. These organizations have also provided practical advice to educational institutions to guide them in developing such programs. However, to the best of our knowledge, no academic researchers have yet developed and tested a theoretical research model that encompasses the recommendations of these four organizations and provides a pedagogical foundation for their suggestions.

The purpose of this paper is the presentation of such a model. Following these introductory comments, the next section further discusses the need for globalizing business education as the primary objective and motivation of this work, followed by public literature reviews regarding the work of the AACSB, Forum EA, the United States Department of Education, and MSU-CIBER. The subsequent section proposes a PACK \& GO theoretical model that encompasses their advice, followed by sections providing an illustrative case example, some pragmatic suggestions for implementation, and a few concluding comments, respectively. 


\section{OBJECTIVE \& MOTIVATION: THE NEED FOR GLOBALIZING BUSINESS EDUCATION}

The world presents a much more complex business environment than it did just two decades ago. Globalization, by which we mean the development of an increasingly integrated worldwide economy, marked especially by free trade, free flow of capital, and the tapping of cheaper foreign labor markets, is not just a buzz word but a reality. The economic playing field has been flattened, giving rise to the clever title of Thomas Friedman's bestselling book - The World is Flat. Most, if not all, business schools now offer an International course in the major business disciplines - Finance, Accounting, Marketing, and Management.

The authors contend that actually going abroad to study these, and other, disciplines provides an educational experience that goes well beyond what is possible in a domestic classroom setting. The study abroad experience enriches the education of both undergraduate and graduate business students by providing direct exposure to different world cultures as reflected in the art, architecture, language and history of the countries that these students visit. This exposure, properly assimilated, we contend, helps these students become well rounded business leaders. This occurs, in part, because students who participate in study abroad programs develop an awareness of, and appreciation for, cultural differences. They gain competence in achieving a global perspective by their experience of the dynamics of history, politics, environment, culture, religion, and global economics outside of the United States.

In developing a study abroad program for schools, colleges, and universities of business, there are several important issues that need to be addressed. This paper presents an innovative model, entitled PACK \& GO, that describes the key elements of such a study abroad program. The model addresses the Philosophy, $\underline{A} s s e s s m e n t$,

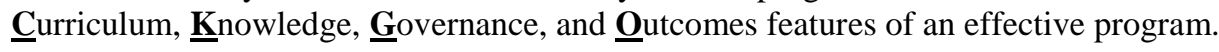

\section{LITERATURE REVIEW}

Any review of the relevant literature regarding innovation in pedagogical program design and implementation must logically encompass four distinct conceptual levels. At Level A, industry authorities establish quality standards to recognize and reward excellence, thereby creating optimal goals for educational institutions. At Level B, academic institutions create collaborative working groups to assist each other in achieving these optimal goals. At Level C, governmental organizations establish minimum requirements to eliminate poor quality programs, thereby creating sets of standards and definitions to regulate the market itself. And at Level D, individual colleges and universities employ their own resources (and access Level B resources) to maneuver their way well past Level C and towards (and, if highly successful, beyond) Level A.

\section{Level A}

The AACSB occupies a uniquely important position in the field of quality standards development and thus represents an ideal reference point for Level A. It describes itself (AACSB, 2009) as "an association of educational institutions, businesses, and other organizations devoted to the advancement of higher education in management education ... the premier accrediting agency of collegiate business schools and accounting programs worldwide." Its membership encompasses over 1,100 organizations in 70 nations across the globe; its accreditation standards have become universally respected guidelines for quality programs across the field of management education.

The July 1, 2009 edition of its Eligibility Procedures and Accreditation Standards for Business Accreditation heavily emphasize the importance of student exposure to global cultures. In fact, the very first sentence of its preamble states that: "Complex demands on management and accounting education mirror the demands on organizations and managers. Challenges come from: strong and growing global economic forces, differences in organizational and cultural values, cultural diversity among employees and customers, and changing technology in products and processes."

The AACSB also produces numerous reports and white papers that emphasize this issue. In its publication Management Education at Risk: Report of the Management Education Task Force to the AACSB-International Board of Directors, it noted that study abroad programs "foster greater global thinking among students," and it 
bemoaned that "the speed of their growth may not be sufficient to satisfy all employers." It also explicitly recommended that "programs should place greater emphasis on skill development for global assignmentssensitivity and flexibility in responding to local conditions, as well as managerial effectiveness in a dispersed operation."

\section{Level B}

The membership of the Forum on Education Abroad encompasses approximately $75 \%$ of the American study abroad market and thus represents an ideal reference point for Level B. Consisting of over 300 academic institutions, Forum EA establishes standards of good practice for study abroad programs and engages in curriculum development, data collection, and outcomes assessment activities (Forum EA, 2008). It has been recognized by the United States Department of Justice and the Federal Trade Commission as the Standards Development Organization (SDO) for education abroad programs.

Its Standards of Good Practice for Education Abroad emphasize the development of a Program Mission (Standard 1) and a focus on Student Learning and Development (Standard 2). The learning and development standard is further subdivided into segments involving Inter-Cultural Understanding (Standard 2a), Language and Communication (Standard 2b), Academic Growth (Standard 2c), and Student Development (Standard 2d). By asking questions such as:

- $\quad$ "are integrative activities designed to assist students in acquiring general adaptive skills that prepare them to live in a cultural milieu different from their own?," and

- $\quad$ "does the program provide mechanisms for fostering students' independence and self-direction ... (e.g., leadership skills, service orientation, maturity, tolerance for ambiguity)?," the standards serve to provide elaborative instructive detail to academic institutions that are striving to meet the general quality standards established by the AACSB.

\section{Level C}

The United States Department of Education (DOE, 2008) is a federal cabinet level organization that establishes policies on federal financial aid, collects data, disseminates research findings, advocates policy positions, and ensures equal access to educational institutions; it thus represents an ideal reference point for Level C. The Department has commissioned the development of numerous studies and papers about the merits of global education programs.

One such study was the landmark Benchmark Study on International Business Education at Community Colleges that was completed in 2008 by Michigan State University and Lansing Community College with a Title VIB grant from the Department of Education. Although not explicitly focused on study abroad programs, the report was noteworthy for its development of a International Business Education Index (IBEX) that creates a uniform ratings score for academic institutions. The score is based on five dimensions (euphemistically referred to as "pillars") of performance, namely: Strategic Commitment, Program Offerings, Organizational Infrastructure, Funding, and Investment in Faculty.

Study abroad programs are explicitly addressed in three of these five dimensions. Question 8 of the Strategic Commitment component of the index is "does your institution have a study abroad program in business?" Question 5 of the Program Offerings component is "what percentage of business students at your institution study abroad?" And Question 1a of the Investment in Faculty component is "does your institution earmark funds for business faculty to participate in ... leading undergraduate students on study abroad?" The similarity of these questions, though they appear in different dimensions, is an indicator of the extent to which study abroad programs can simultaneously impact numerous goals of academic organizations. 


\section{Level D}

Hundreds of colleges and universities publish articles and other materials that describe how they establish study abroad practices that exceed minimum guidelines (i.e. Level C) and meet or exceed various standards of excellence (i.e. Level A). One such institution is Michigan State University, the creator of the aforementioned IBEX and the holder of a Department of Education designation as a National Resource Center for International Business Education and Research (CIBER).

Michigan State's International Business Center has received funding from the U.S. Department of Education, National Science Foundation, U.S. Department of State Bureau of Educational and Cultural Affairs, U.S. Small Business Administration, U.S. Agency for International Development, U.S. Information Agency, and numerous other public and private agencies that are dedicated to preparing American students for global business careers (MSU 2002). The Center publishes numerous reports that analyze global education trends and present recommendations for study abroad and other academic initiatives.

In a 2002 report entitled Study Abroad Programs in Business Schools: Issues and Recommendations by Leading Educators, MSU joined twelve other major American institutions in a roundtable initiative that resulted in recommendations regarding the definition of best practices and the development of anticipated outcomes in study abroad programs. For instance, it suggested the following best practices as guidelines for American institutions: field trips to foreign firms and other overseas organizations, experiential class projects and study tours, and integrated programs from multiple academic departments. Furthermore, it also suggested the development of measurements that assess the following outcomes: academic progress and intellectual development, attitudes, skills, understanding and appreciation of the world and one's place in it, and effect of one's place in society.

The literature cited above represents a small but highly significant and representative slice of the numerous volumes of material published about global business education during the past decade. Across the four levels that we have defined herein, a number of important themes have proven pervasive: namely, an educational philosophy and governance structure that emphasizes exposure to global cultures and knowledge, a learning environment that features experiential curricular activities, and assessment activities that produce measurable outcomes. These common themes serve as the foundations of our PACK \& GO theoretical model; we define its components in the following section.

\section{THE PACK \& GO MODEL}

The following section describes the six elements of the PACK \& GO theoretical model.

\section{Philosophy}

The philosophy of the program establishes, in the first place, the reasons for having a study abroad program for business students, or at least one in which business students can participate, and whether the university should maintain its own program or outsource. Initially, study abroad programs were designed to meet the needs of foreign language students and were offered through the university's foreign language department. The reasons of these "total immersion" programs were obvious and the benefits immediate. Almost as obvious were the benefits of study abroad to students of history, fine arts, and religious studies. Seeing Michelangelo's David in person, or walking through the Roman Forum, or visiting the principal synagogue or mosque in Paris, provides a much richer experience than seeing slides of these things on a screen in a classroom setting in the U. S.

Until recently, however, reasons for business students to study abroad were not quite as compelling. It was enough for principles of marketing, finance, and management to be taught and understood in a domestic context. That all changed with the advent of multinational corporations, new and more liberal free-trade agreements, increasing dependence on less expensive foreign labor, in short, with the advent of a well integrated global economy. 
Today, if their companies are to survive and thrive, business leaders must be aware of global opportunities, global competition, and global political and social issues. They must be aware of the rewards and risks associated with international trade, marketing, and finance. What better way than studying abroad is there to accomplish these goals.

Establishing a study abroad program in any country requires a significant commitment of the university's resources and involves legal risks that outsourcing does not. Nevertheless, most universities maintain some of their own programs and outsource others. One of the principal benefits of maintaining ones own program is faculty development. It is quite a rewarding and enriching experience for a faculty member to travel abroad to teach in another country. In addition the issue of transfer versus home school credit must be addressed when deciding which strategy to pursue.

\section{Assessment}

The issues to be addressed with respect to assessment are: What are the immediate and longer-term measurable objectives for business students? Is there a link to AACSB accreditation standards? What program design supports (or detracts) from the stated objectives of the program? How will outcomes be measured?

From the student's perspective, an immediate goal is to successfully complete 3 or 6 credits of course work. In doing so, however, the designers of the program should expect their students to gain a appreciation of the culture of the country they visit, to acquire a degree of independence and self-sufficiency, perhaps through travel, not possible at home, to understand that citizens of other countries may have significantly different political views from their own and perhaps be prepared to intelligently discuss their own views, to learn something about foreign exchange, and to increase their knowledge of world geography. Employers tend to look favorably on students who have studied abroad and improving one's resume may also be a goal for students.

Aside from the length of the program - short-term summer, semester-long, or year-long - there are essentially two different program designs: "Island Programs" where domestic students are taught in isolation, in their own language, by their own professors, but in a foreign country, and "Immersion" programs, where domestic students are placed in existing foreign university classes among foreign students, and taught by foreign professors in perhaps, but not always, the foreign language. Some programs have aspects of both and there are advantages and disadvantages of each.

The usual assessment instruments, in which students have an opportunity to evaluate their courses and professors generally serve the program designers well, provided that the students have opportunities to also evaluate their cultural experiences, their housing facilities, their meal plans, and other elements, such as pre-departure preparation, orientation, and post-trip debriefing that are unique to a study abroad program. Teaching faculty should also prepare a critical report for the program director.

\section{Curriculum}

An important question to be answered here is: Should curriculums for study abroad courses differ from U. S. equivalent courses? We believe that the answer is "yes!" They should include on-site tours, special projects that involve learning about foreign business practices, guest lectures by leaders of foreign firms or branches of multinational corporations, visits to foreign stock exchanges, bond markets, embassies, etc. Also, business students should be encouraged to take at least one foreign language, history, or fine arts course. A well rounded business student is more likely to become a future business leader. A commonly occurring question to be addressed in this respect is whether business students should be required to become proficient in a foreign language. If a particular university answers this question in the affirmative, then study abroad is an obvious means to that end.

In "Immersion" programs students have to be made aware of the different ways in which students are expected to participate in the educational experience and how they will be graded as a result. In the British/Australian system, students are expected to be much more independent learners and are graded more rigorously than are students at some U.S. universities. 
Curriculum design and approval could be an issue in terms of accreditation standards. AACSB standards are those that most business schools will want to review with respect to curriculum design.

\section{Knowledge}

In designing a study abroad program for business students, one would want to be able to list and explain what skills these students will gain from study abroad that are not achievable at the home university. Meeting, interacting, and discussing business practices with foreign students is an obvious benefit. Therefore the program's design should encourage these interactions. In "Immersion" programs, teams consisting of both domestic and foreign students can be formed to work on a business case or group project. Foreign internships, now available in many countries, are an exciting and interesting way to learn about foreign business practices. By traveling and having to deal with exchange rate fluctuations, students become much more aware of world geography and money management issues than if they were to simply read about these issues in a book.

Unless one is completely closed to new experiences, simply living in a foreign country for a period of time ensures that one will absorb a certain knowledge of its history, its culture (food, work ethic, religious beliefs, etc.), and its political concerns.

Program designers should be prepared to address objections to study abroad. Some common objections are that the courses are less rigorous, that there is insufficient time spent in the classroom, that the cost is prohibitive, that the value to ones future career is not clearly articulated, etc. Addressing these objections, at least, should be reasonably straight forward.

\section{Governance}

Governance is a major issue and addresses concerns about: What rules and laws govern the students when living aboard? What is the student discipline process in the event of a problem? What is the ideal organizational structure for a study abroad function? What are "best practice" checks and balances?

Usually the laws of the host country apply with regard to things like the drinking age (in many European countries, the drinking age is 18), habeas corpus, drug violations, etc. However, there are exceptions. For example, U.S. law applies in cases of sexual harassment, even though such harassment occurs in the foreign country.

Despite good screening processes involving interviews, letters of recommendation, essays discussing background and motivation, and a review of student records for disciplinary sanctions and minimum GPA, the designer of a study abroad program must expect and be prepared to deal with problems. Generally the home university's rules of student conduct should apply and students should be sent home for serious violations.

The ideal structure for the study abroad function would be a study abroad office with a full-time director, several program coordinators, and at least one full-time support staff member to handle clerical work, answer phone calls, and collect money, etc.

With regard to best practices, students planning to travel on their own during free periods, should be advised to check State Department warnings. Students should be required to sign legal waivers, and other documents stating that they have adequate health insurance that applies overseas, that they agree to certain behavioral standards, that they have personal liability insurance, etc. Teaching faculty should be required to participate in an orientation program designed to alert them to their responsibilities while participating in the study abroad program, but also what opportunities there are for doing research.

\section{Outcomes}

In this last design phase, different from assessment, the focus is on overall long-term results. Knowing what was expected or anticipated before the program commenced, the question to be answered here is: Did the 
program achieve its goal? Analysis of the evaluation forms, mentioned above, will be of some help here, but a longer-term perspective is necessary.

Interviews with student's who participated in study abroad, conducted after graduation, will be helpful in answering questions about whether, or to what extent, the study abroad experience helped in the job search efforts. The interview should include questions regarding what aspects of the study abroad experience were helpful to the student in achieving their personal and professional goals. What would have made the study abroad experience more useful in the career path they chose?

Outcomes for faculty should also be assessed. For example, did the study abroad experience actually provide anticipated research opportunities. If so, was a paper or book published? Was the study abroad experience helpful in achieving longer-term career development goals?

Some effort should be made here to determine if successful outcomes were a function of the country of study or the design of the program in that country - the courses offered, the excursions, the site visits, etc.

\section{ILLUSTRATIVE EXAMPLES}

To illustrate the concepts discussed above, we have chosen three study abroad programs offered by Iona College. Iona has been offering study abroad programs, developed by its own faculty and administrators, for over 25 years. Iona students can spend a year, a semester, or part of a summer abroad studying a wide range of college subjects in 7 different countries (England, Ireland, Australia, Italy, Spain, France, and Greece), and plans for expanding into Asia and Africa are currently being considered. The three programs that we will use to illustrate the PACK \& GO model are: (1) a summer program offered in Rome, Italy, (2) a semester program offered in Fremantle, Australia, and (3) a junior year abroad program offered at Oxford University. Aspects of the PACK \& GO model will be highlighted within the discussion of these three programs. Although all three of these programs involve all elements of the PACK \& GO model, in discussing the Rome program we focus on Philosophy and Assessment, in discussing the Australia program we focus on Knowledge and Governance, and in discussing the Oxford Program we focus on Curriculum and Outcomes.

\section{Rome, Italy}

Iona College offers a five-week summer program based in Rome, Italy, but which also includes a four-day visit to Florence. Besides a language, an art, a religion, and a history course, two business courses are offered International Law and Business and The Role of Business in Contemporary American Society. The former provides an introduction to different aspects of public and private international law and covers such topics as international law and international organizations, the conflict of laws, and Islamic law traditions, to name a few. The latter covers topics such as global competition, global political and social issues, and managing technological change among others. Aspects of finance, management, and marketing are covered in both courses. Under the current program design, Iona students do not take classes with Italian students. However, Iona students are encouraged to go out into the surrounding community and meet with the locals. They are asked to keep a journal to record what they notice about the differences between Italian and American social, commercial, and professional life. Often they make friends with local shopkeepers, their landlords, and Italian students that they meet at clubs and restaurants. In the classroom, they examine case studies involving multinational corporations which focus on global legal, environmental, and ethical issues. Opportunities abound for students to visit Italian corporations and speak to their managers about issues discussed in class. Faculty from Iona travel to Italy with the students and teach these two courses and are joined in Italy by Italian faculty from the University of Rome who teach some of the others. The philosophy of the program is to provide a rich international learning and teaching experience for both students and faculty. Often, both Iona students and Iona faculty report that the experience is life-changing.

In the Rome program, a detailed assessment instrument is used to determine if the objectives of the program have been met. It covers the usual issues related to the course itself - objectives, content, professor competence, course materials, etc. However, it also covers all aspects of the study abroad experience - orientation, housing, meals, excursions and site visits, medical needs, social challenges, pre-departure preparation, and more. 
Students are asked questions about aspects of Italian culture - what they found most interesting, most different, most difficult to understand, etc. One element that is quite helpful is a post program debriefing when students have had a chance to reflect on the study abroad experience after they return to more familiar surroundings. The faculty are also asked to write a report about the program, in which they comment on the students, the program design, the study environment, and whether they believe the program objectives were met.

\section{Fremantle, Australia}

Iona College also offers a semester-long program hosted by the University of Notre Dame Australia (UNDA) located in Fremantle on the West Coast of Australia. This program is quite different from the Rome summer program in a number of ways. First, except for the Australian History and Culture course, which all study abroad students must take, Iona students take courses with Australian students in UNDA classes. Thus, they interact and participate in group study with Australian students. Over the course of a 17-week semester, the Iona students often meet and become close friends with Australians studying at UNDA. Second, a broad range of courses from the UNDA catalog are available for the Iona students to take, depending on their major and their elective interests. This makes the program a little more complex to administer in that departmental approvals are required for each course that a student wishes to take, to ensure that credit will be granted by Iona. Third, the British system of teaching in Australia is quite different from that at Iona College and students need to be aware of the differences in grading procedures, the level of independent learning required, and the expectations of Australian professors. Fourth, and finally, the Iona students travel to Fremantle on their own and are not accompanied nor taught by Iona professors.

As a result of these differences, a higher level of maturity and a higher GPA is required for a student to participate in the Australia Program. Whereas the Rome summer program is open to all students with a GPA of 2.5 or higher, students attending UNDA for a semester must be either Juniors or Seniors and have a minimum GPA of 3.0. The students' disciplinary records are carefully scrutinized and students on probation, or with disciplinary sanctions on their record, are prohibited from participating. Two letters of recommendation are required and interviews are conducted as part of the screening process. During the interviews students are made aware of issues regarding Australian law, UNDA disciplinary processes, and several Australian government requirements.

One attractive aspect of the Australian program for business students is a course offering entitled "Business in Asia." This course includes a week-long trip to Singapore to meet with business leaders in that country and to explore aspects of international trade, finance, and politics that affect their companies. In combination with two or three other business courses business students can earn a "Business Certificate" attesting to their broad international business exposure in classes taken at UNDA. This is truly an "immersion" program which provides an enriching experience not available at home.

\section{Oxford, Great Britain}

Iona College also offers a junior year abroad program at Oxford University. This program is open to two juniors at Iona College who have a minimum GPA of 3.5 and who successfully compete for a scholarship to attend Oxford University during their junior year. The curriculum design is quite different from any other that students are likely to experience at any other time in their lives. Students are required to take two tutorials per trimester in nonbusiness subjects. They can choose from Philosophy, History, English, or Theology. They supplement these tutorials with lectures in subjects according to their major requirements at Iona. Business students who participate in this program often attend lectures on Economics, Commerce, and International Business. The tutorial system is unique to Oxford and Cambridge. One tutorial at Oxford involves eight meetings during one trimester - one meeting per week - with a tutor from one of the Oxford colleges. At these meetings a student's work is critically reviewed and new work is assigned for the next meeting. The focus of these meetings is primarily on content, but also on the student's ability to write clearly and defend a position logically. Preparation on the part of the student is crucial. These tutorial sessions can be quite intense for a student not used to the tutorial system. 
Opportunities to travel in Europe and Asia abound, since, between each of the trimesters, there is a sixweek break. Since the year 2000, 19 Iona students have participated in this program at Oxford University and most have taken advantage of this opportunity to travel.

In an effort to assess long-term outcomes, students are contacted and asked in what ways the Oxford experience helped them to achieve academic, personal, and professional goals. Below is a representative quote from a former Iona student - Anthony DeMieri - who participated in this program in the academic year 2000-2001:

"Studying at Oxford University during my junior year of college was one of the most memorable and significant experiences of my life. I studied a wide range of subjects among the brightest minds in the world. I fondly recall defending my weekly thesis papers, attending lectures, and participating in several extracurricular activities available to visiting students. I had the rare opportunity to travel around most of Europe during winter break while I was in England. Some of the countries that I had a chance to visit include: Italy, France, Germany, Switzerland, Austria, and Holland. Reflecting back to my studies at Oxford, the experience has given me tremendous confidence to tackle any task. I am well trained to handle situations that require rapid decision making, solid communication, and precise thinking. Without reservation, I am well prepared for the rigors of doctoral studies and life beyond the university. In applying for the position that I have now, I know that I was chosen over several other well qualified candidates because of my Oxford study abroad experience. I am forever thankful to my professors at Iona who inspired me and encouraged me to take advantage of this marvelous opportunity."

\section{RECOMMENDATIONS AND CONCLUSION}

The purpose of this article is to describe a theoretical research model for defining the characteristics of effective study abroad programs for the benefit of students like Anthony DeMieri. Our model, defined by the acronym PACK \& GO, synthesizes guidance from organizations, such as the AACSB, Forum EA, the United States Department of Education, and MSU-CIBER, by presenting a set of six factors that encompass the philosophy, assessment, curriculum, knowledge, governance, and outcomes features of effective learning programs.

Pragmatically speaking, though, how should faculty members of globally oriented academic institutions begin to address their institutional needs to develop study abroad initiatives? What steps should they take to develop, implement, and then assess such programs in accordance with our PACK \& GO model?

Based on the experiences of Iona College in conducting hundreds of study abroad programs, including the three illustrative examples presented in the Illustrative Examples section of this article, we recommend that faculty members focus on the following developmental activities:

\section{Perform A Self-Assessment of Your Institutional Needs}

Conduct surveys, polls, and outreach activities to assess the level of student interest in study abroad opportunities, as well as the extent to which administrative resources are available to support such initiatives. At Iona College, for instance, a Study Abroad Outreach Program is presented during each annual Student Club Day to explain the benefits and obligations of the study abroad option and to assess whether there is sufficient student interest to support prospective enhancements.

\section{Gather Information from Knowledgeable Sources}

Although guidance from organizations such as the AACSB, Forum EA, the United States Department of Education, and MSU-CIBER can be helpful, supplemental step-by-step advice on a broad array of practical subjects may be effectively gleaned from live presentations at academic conferences. The week-long annual conference and expo of NAFSA, once known as the National Association of Foreign Student Advisers and now more broadly defined as the Association of International Educators (NAFSA, 2009), offers one such venue for learning about processes for organizing study abroad programs and developing assessment models. 


\section{Compare Outcome Data and Define Best Practices in Collaboration with Partner Institutions}

Identify a cohort group of similar colleges and universities that are also creating and/or enhancing study abroad programs, and meet with them on a periodic basis to compare approaches, experiences, and learning outcomes. Iona College, for instance, collaborates with representatives from Fordham University, Manhattan College, St. John's University, and six other academic institutions through an organization known as the Lower Hudson Valley Consortium of Catholic Colleges \& Universities.

Colleges and universities that seek to globalize their curricula to emphasize the impact of international and intercultural issues on American business organizations often begin to do so by incorporating written cases and internet-based communication methods in the lesson plans of relevant courses. Academic institutions that wish to take the next logical step, by requiring students to physically travel to international locations for significant learning experiences, may benefit by conducting these activities in order to develop study abroad programs in accordance with our PACK \& GO research model.

\section{AUTHOR INFORMATION}

Dr. George A. Mangiero is an Associate Professor of Finance and Economics at Iona College in New Rochelle, New York. His research interests are primarily in the areas of Portfolio Management, Financial Futures, Options and Swaps, and Corporate Finance. Dr. Mangiero's graduate degrees include an MS in Electrical Engineering, Rensselaer Polytechnic Institute, an MBA in Finance, St. John's University, and an M.Phil. and Ph. D. in Finance, New York University. He resides with his wife in Connecticut.

Michael Kraten, PhD, CPA is an Assistant Professor of Accounting at Providence College in Providence, Rhode Island. $\mathrm{He}$ is also the President and co-founder of Enterprise Management Corporation, a strategic management consulting firm in Milford, Connecticut, and has earned a Ph.D. in behavioral accounting from the University of Connecticut. He has also earned an M.P.P.M. in management from Yale University and a B.B.A. in public accounting from Baruch College of the City University of New York.

\section{REFERENCES}

1. AACSB (2009). Eligibility Procedures and Accreditation Standards for Business Accreditation. AACSB International. Tampa, FL: Adopted April 25, 2003 and Revised July 1, 2009.

2. DOE (2008). Benchmark Study on International Business Education at Community Colleges. International Business Center of the Eli Broad College of Business of Michigan State University. East Lansing, MI: 2008.

3. Forum EA (2008). Standards of Good Practice for Education Abroad. The Forum on Education Abroad. Carlisle, PA: 2008.

4. MSU (2002). Study Abroad Programs in Business Schools: Issues and Recommendations by Leading Educators. Michigan State University. East Lansing, MI: May 2002.

5. NAFSA (2009). NAFSA 2010 Annual Conference \& Expo. NAFSA: Association of International Educators. Washington, DC: Available at http://www.nafsa.org on September 7, 2009. 